\title{
The Ebre Observatory seismological station: past and present instrumentation and noise conditions
}

\author{
Arantza Ugalde \\ Observatori de l'Ebre, Roquetes (Tarragona), Spain
}

\begin{abstract}
A review of the past and present instrumentation at Ebre Observatory seismological station (EBR) is presented in this work. In order to assess the quality of EBR from the point of view of modern seismic instrumentation site requirements, the noise conditions at EBR are also investigated by means of velocity power spectral density analysis in the frequency band $0.01<f<15 \mathrm{~Hz}$ by exploiting the three component broadband and digital data processing current capability. A correlation between noise levels and meteorological conditions at the site is observed, using the data of a complete meteorological station located a few tens of meters from the seismic cave. Results show that for long periods $(f<0.04 \mathrm{~Hz})$ and wind speeds ranging from 0 to $15.5 \mathrm{~m} / \mathrm{s}$, seismic noise levels may vary up to 45 $\mathrm{dB}$ for the horizontal components. These variations are related to tilts due to wind-generated pressure fluctuations. Secondly, the seasonal variation of noise levels at the frequency band $0.04<f<0.3 \mathrm{~Hz}$ is characterized, obtaining that the amplitude of the seasonal variation is higher for secondary (up to $52 \mathrm{~dB}$ ) than for primary (up to $44 \mathrm{~dB}$ ) microseisms. On the other hand, a seasonal variation of the frequency of the three-component main noise peak is also suggested in this site and its variation is opposite to the velocity power spectral density amplitude evolution. Finally, a correlation between wind speed and seismic background noise is also observed at high frequencies.
\end{abstract}

Key words EBR station - instrumentation - seismic noise

\section{Introduction}

The Ebre Observatory seismological station, with geographical coordinates $40^{\circ} 49.23^{\prime} \mathrm{N}$ and $0^{\circ} 29.60^{\prime} \mathrm{E}$ (fig. 1) has been operating different seismographs almost without interruption since its foundation in 1904. It is sited at a distance of about $20 \mathrm{~km}$ from the Mediterranean Sea coast and at about $2.5 \mathrm{~km}$ from the Ebre river. The station is close to the towns of Roquetes and Tortosa and is located in a cave, $7 \mathrm{~m}$ in

Mailing address: Dr. Arantza Ugalde, Observatori de l'Ebre, Hora Alta 38, 43520 Roquetes (Tarragona), Spain; e-mail: augalde@obsebre.es depth, on an approximately $300 \mathrm{~m}$ depth cover of Quaternary sediments over a Cretaceous basement. EBR recordings, more than 100000 original seismograms from all the seismographs that have been operating, have been kept up to the present and are of key importance for the instrumental study of Western Mediterranean seismicity (Batlló and Cardús, 1993; Susagna et al., 1997). The series of seismograms preserved are complete: it constitutes the longest series preserved in Spain, and a preliminary comparison with the main earthquakes of this century (Richter, 1958) shows that the Observatory only missed 17 of the 127 events that should have been recorded. Most of the lost events correspond to periods in which the seismographs were stopped (Batlló and Cardús, 1993). In the following, a brief outline of the evolution of the instrumentation at EBR since its foundation almost 100 years ago will be given. 


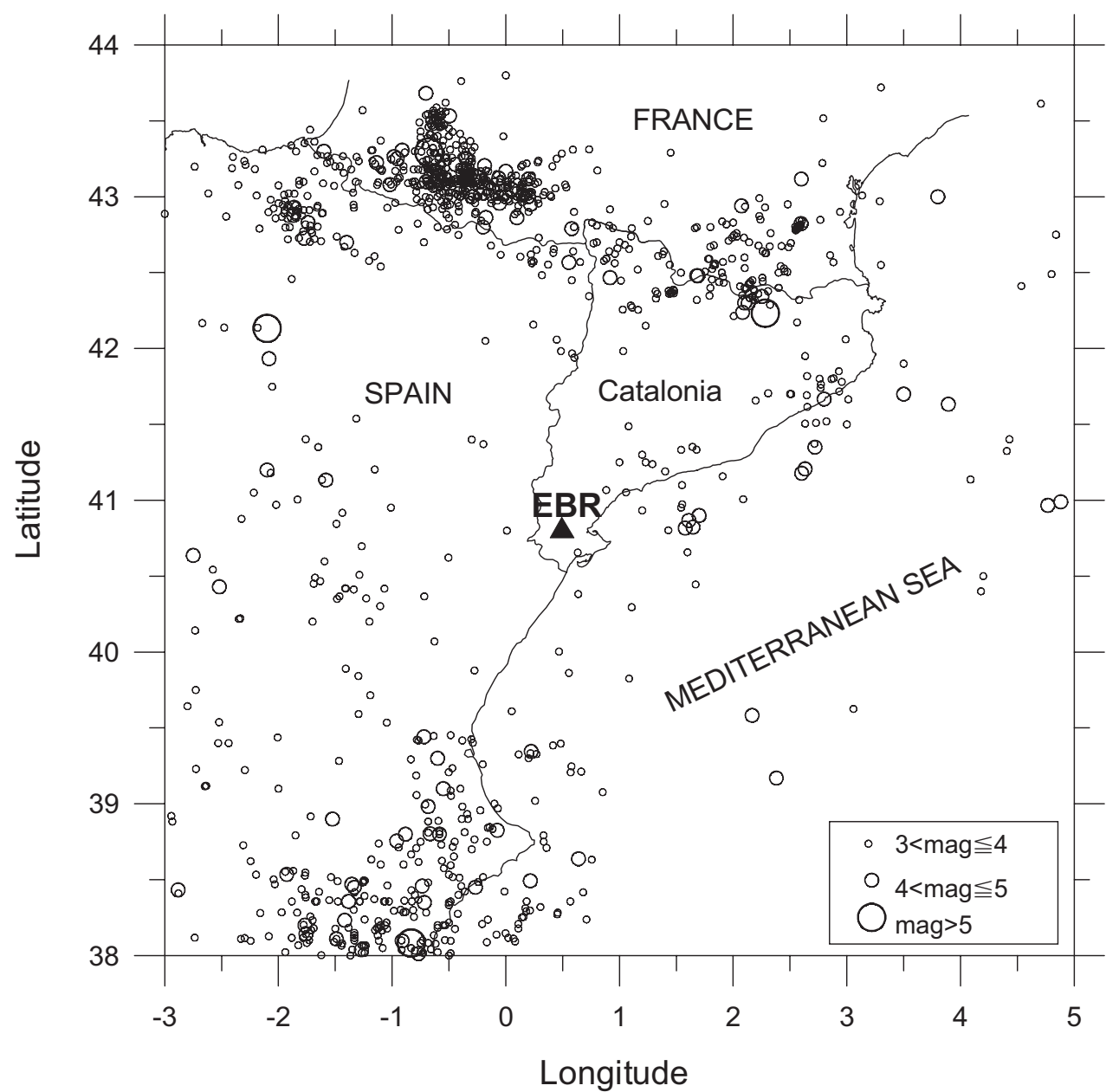

Fig. 1. Map showing the station location and surrounding seismicity. Earthquakes with magnitudes greater than 3 occurring up to February 2003, according to the seismic of the Istituto Geográfico Nacional (Spain), are plotted.

EBR station was set up in the past as a part of an Observatory devoted to the study of Solar-Terrestrial Physics. Thus, it was installed following not exclusively seismological site selection criteria. However, the quality of any seismic station and its level of detectability strongly depend on seismic site characteristics. At present, a seismic noise characterization of EBR site has been possible by exploiting the three component broadband and digital data processing current capability. The aim of this work is the quantification of noise levels in order to assess the quality of the station for the frequency band ranging from 0.01 to $15 \mathrm{~Hz}$. The noise level will be studied by means of a velocity power spectral density analysis applied to different frequency ranges, according to the classification of Haubrich (1967), which are related to different noise source processes. Long period seismic noise $(f<0.04 \mathrm{~Hz})$ may 
Table I. Different seismographs that have operated at the Ebre Observatory together with their characteristics: name of the seismograph, time period of operation, type (M: mechanical; E: electromagnetic), component, mass of the pendulum, period, damping factor, friction factor, amplification factor, polarity and recording velocity in millimetres per minute (Batlló and Ugalde, 2000). Values in brackets are not known certainly.

Seismographs of the Ebre Observatory

\begin{tabular}{|c|c|c|c|c|c|c|c|c|c|c|}
\hline Instrument & Years & $\mathrm{T}$. & Comp. & $\begin{array}{c}\text { Mass } \\
(\mathrm{kg})\end{array}$ & $\begin{array}{l}\text { Per. } \\
\text { (s) }\end{array}$ & Damp. & Frict. & Ampl. & Pol. & $\begin{array}{l}\text { Rec. } \\
\text { vel. }\end{array}$ \\
\hline Grablovitz & 1904-18 & M & NE-SW & 12 & 13 & - & & 8 & & 5 \\
\hline Grablovitz & 1904-18 & M & NW-SE & 12 & 13 & - & & 8 & & 5 \\
\hline Vicentini & 1904-36 & M & $\mathrm{Z}$ & 50 & 0.85 & - & 0.008 & 150 & $\mathrm{Up} \uparrow$ & 15 \\
\hline Vicentini & 1904-13 & M & $\mathrm{N}-\mathrm{S}$ & 100 & 2.3 & - & 0.02 & 90 & $\mathrm{~N} \uparrow$ & 15 \\
\hline Vicentini & 1904-13 & M & E-W & 100 & 2.3 & - & 0.02 & 90 & $\mathrm{E} \uparrow$ & 15 \\
\hline Vicentini & 1914-16 & M & $\mathrm{N}-\mathrm{S}$ & 100 & 2.3 & - & 0.02 & 90 & $\mathrm{~N} \downarrow$ & 15 \\
\hline Vicentini & 1914-28 & M & E-W & 100 & 2.3 & - & 0.02 & 90 & $\mathrm{E} \uparrow$ & 15 \\
\hline Mainka & 1914-41 & M & $\mathrm{N}-\mathrm{S}$ & 1501 & 14.8 & $\sim 0.4$ & 0.005 & 200 & $\mathrm{~N} \uparrow$ & 12 \\
\hline Mainka & $1914-41$ & M & E-W & 157 & 7.8 & $\sim 0.3$ & 0.005 & 110 & $\mathrm{E} \downarrow$ & 12 \\
\hline Vertical p. & 1914-15 & M & NE-SW & 316 & $(2.5)$ & - & & & & 12 \\
\hline Vertical p. & 1914-15 & M & NW-SE & 316 & $(2.5)$ & - & & & & 12 \\
\hline Vertical p. & $1915-41$ & M & $\mathrm{N}-\mathrm{S}$ & 316 & 2.6 & - & 0.002 & 125 & $\mathrm{~N}$ & 12 \\
\hline Mainka & $1942-66$ & M & $\mathrm{N}-\mathrm{S}$ & 1500 & 15.4 & $\sim 0.4$ & 0.004 & 275 & $\mathrm{~N} \uparrow$ & 12 \\
\hline Mainka & $1942-66$ & M & E-W & 1500 & 10.8 & $\sim 0.4$ & 0.003 & 150 & $\mathrm{E} \uparrow$ & 12 \\
\hline Vertical $p$. & $1942-61$ & M & $\mathrm{N}-\mathrm{S}$ & 635 & 2.5 & - & 0.004 & 230 & & 12 \\
\hline Vertical p. & 1961-66 & M & $\mathrm{Z}$ & 635 & & - & & & & 12 \\
\hline Benioff & 1966- & $\mathrm{E}$ & $\mathrm{Z}$ & 15 & 15 & & - & 50000 & $\mathrm{Up} \uparrow$ & 60 \\
\hline Benioff & 1966- & $\mathrm{E}$ & $\mathrm{N}-\mathrm{S}$ & 14.75 & 15 & & - & 50000 & $\mathrm{~N} \uparrow$ & 60 \\
\hline Benioff & 1966- & $\mathrm{E}$ & E-W & 14.75 & 15 & & - & 50000 & $\mathrm{E} \uparrow$ & 60 \\
\hline Sprengnether & 1968-00 & $\mathrm{E}$ & $\mathrm{N}-\mathrm{S}$ & 10.7 & 1.0 & & - & 1500 & $\mathrm{~N} \uparrow$ & 15 \\
\hline Sprengnether & 1968-00 & $\mathrm{E}$ & E-W & 10.7 & 1.0 & & - & 1500 & $\mathrm{E} \uparrow$ & 15 \\
\hline Sprengnether & 1969-00 & $\mathrm{E}$ & $\mathrm{Z}$ & 11.2 & 1.0 & & - & 1500 & $\mathrm{Up} \uparrow$ & 15 \\
\hline SS-1 Ranger & $1987-$ & $\mathrm{E}$ & $\mathrm{Z}$ & 1.45 & 1.0 & & - & & & 60 \\
\hline SS-1 Ranger & 1991- & $\mathrm{E}$ & $\mathrm{N}-\mathrm{S}$ & 1.45 & 1.0 & & - & & & 60 \\
\hline SS-1 Ranger & 1991- & $\mathrm{E}$ & E-W & 1.45 & 1.0 & & - & & & 60 \\
\hline
\end{tabular}


be larger for the horizontal than for the vertical component. This effect is mainly due to tilt, caused by traffic, wind or local fluctuations of barometric pressure, which couples gravity into the horizontal components. Sorrells et al. (1971) observed that during windy intervals, earth motion caused by the turbulent atmospheric pressure field can contribute substantially to the seismic noise recorded at the surface within the period range 20-100 s. Beauduin et al. (1996) also concluded that atmospheric pressure fluctuations can disturb a seismometer even in a seismic vault, and proposed a technique to correct the seismic signals from the atmospheric pressure noise. Long-period noise may also be caused by air circulation in the seismometer vault or underneath the sensor cover, which can be avoided with stable instrument installations and good shielding (Borrmann et al., 1997). Primary ocean microseisms $(0.04<f<0.08 \mathrm{~Hz})$ are generated by means of the conversion of water waves into seismic energy in shallow waters in coastal regions. On the other hand, secondary or double-frequency ocean microseisms are related to the dominant peak frequencies around 0.16 Hz. They were explained by Longuet-Higgins
(1950) as being generated by non-linear pressure perturbations in the ocean bottom caused by the coupling of ocean waves of equal wavelengths traveling in opposite directions (Cessaro, 1994; Friedrich et al., 1998). High frequency seismic noise $(f>0.5 \mathrm{~Hz})$ may have natural causes such as wind. Withers et al. (1996) and Young et al. (1996) showed that surface high frequency $(1<f<60 \mathrm{~Hz})$ noise levels are strongly correlated with wind speed. Nevertheless, the dominant sources of high frequency noise are man-made and are significantly attenuated with depth. A detailed discussion on causes and characteristics of ambient seismic noise can be found in Borrmann (1999).

\section{Past and present instrumentation}

The number of seismographs operating at EBR are technically more than twenty, because many of them have been modified during the Observatory's operational life (Susagna et al., 1997; Batlló and Ugalde, 2000) (table I). The first instruments installed were, on the one hand, a Grablovitz seismograph, with a rather

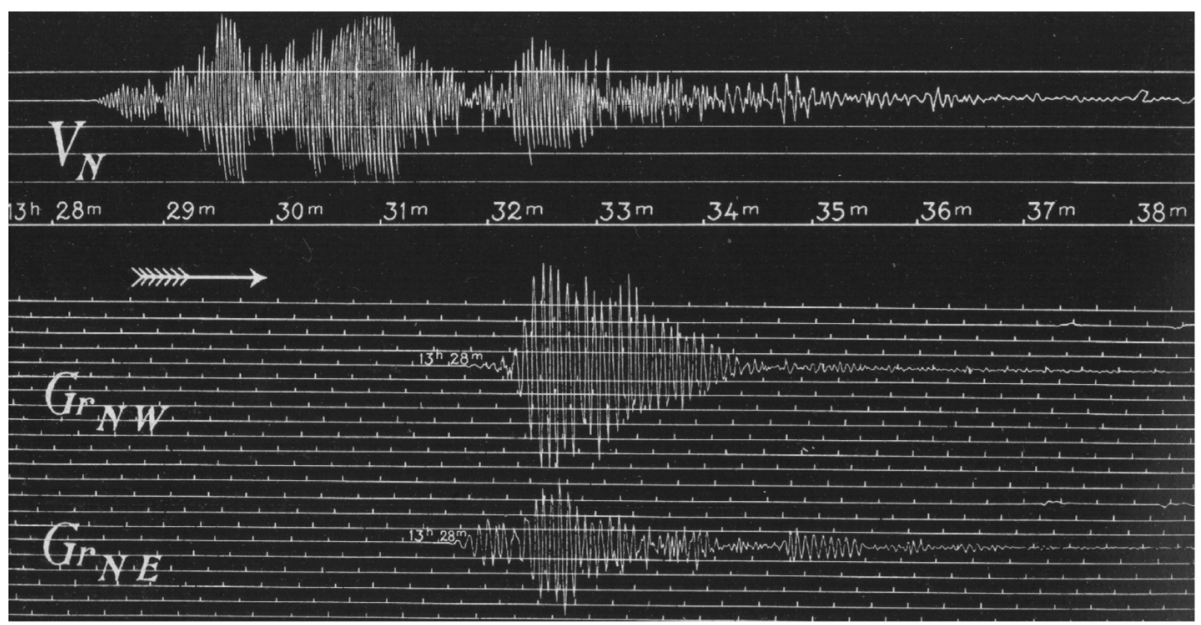

Fig. 2. Example of the recording of an earthquake which occurred in Aumale (Algeria) on June 24, 1910. $V_{N}$ is the north component of the Vicentini seismograph and $\mathrm{Gr}_{\mathrm{NW}}$ and $\mathrm{Gr}_{\mathrm{NE}}$ are the NW-SE and NE-SW components of the Grablovitz seismograph, respectively. 
long period, which was very useful for detecting teleseisms, and on the other hand, a short period Vicentini microseismograph recording the three components, which was suitable for recording regional earthquakes (see fig. 2 for an example of the mechanical recordings on smoked paper). The seismographs of the Observatory were modernized in 1914 with the installation of a Mainka type horizontal seismograph and a vertical pendulum, both built at the Observatory. In 1942, the instrumentation was improved by the construction of two horizontal Mainka type seismographs of $1500 \mathrm{~kg}$ and a vertical pendulum of $635 \mathrm{~kg}$. In 1966, EBR was equipped with electromagnetic seismographs with galvanometric recording. First, three Teledyne Geotech, Benioff type, short period seismographs were installed and later, in 1968-1969, three Sprengnether long period seismographs completed the instrumentation. In 1974, the short period photographic recording was changed to ink by means of some Lennartz electronic amplifiers. The Instituto Geográfico Nacional (IGN) in collaboration with the Ebre Observatory, installed (in 1987 the vertical component and in 1991 the horizontal components) a short period three component seismic station $8 \mathrm{~km}$ from the Observatory. The FM-modulated signals of the three Kinemetrics SS-1 Ranger seismographs are sent to the Observatory where ink recording is performed. From the Observatory, seismic signals were sent to the IGN in Madrid by a dedicated telephone line, where they were digitized. The Institut Cartogràfic de Catalunya in
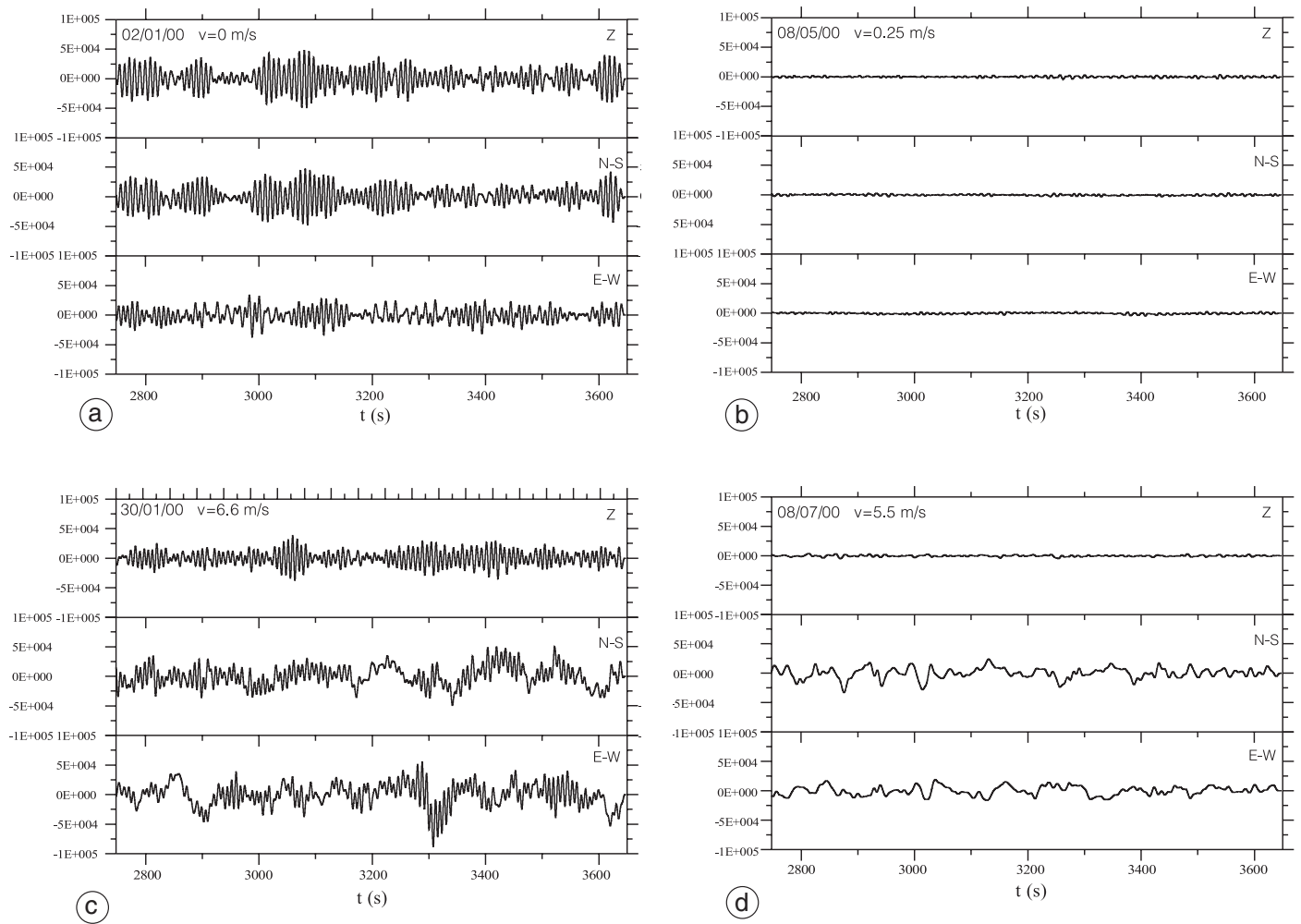

Fig. 3a-d. Original (without correcting for instrumental response) noise recordings of EBR station in winter (a and $c$ ) and in spring and summer (b and d) for different average wind speed (calm and windy periods). 15 min length three-component recordings starting at 3:00 local time are plotted. 
Barcelona also receives the data on-request via telephone.

At present, the EBR station is equipped with a Wielandt-Streckeisen STS-2 seismometer with a flat velocity proportional response characteristic in the frequency range $8.33 \mathrm{mHz}$ to $40 \mathrm{~Hz}$ and a 24-Bit Quanterra Q680-LV datalogger. The EBR station contributes data to the Virtual European Broadband Seismograph Network as part of the MEREDIAN (MediterraneanEuropean Rapid Earthquake Data Information and Archiving Network) real-time data exchange initiative. In this sense, data streams from the SeisComP/SeedLink server are collected by the Antelope real-time system at the ORFEUS data centre.

It is worth adding that all seismological data since the first recorded earthquake on April 25, 1905 to date are available on request.

\section{Analysis of noise conditions}

From June 1999 to November 2000, a temporary broadband seismic station was operating at EBR. It consisted of a STS-2 seismometer with a MARS-88 data acquisition system belonging to the Institute of Geophysics (ETH, Zurich) and was part of the MIDSEA (Mantle Investigation of the Deep Suture between Eurasia and Africa) Project, which aims to study the structure of the lithosphere along the Eurasia-Africa plate boundary. In order to reduce the influence of thermal fluctuations, a double thermal shielding was applied to the seismometer. First, the STS-2 was tightly wrapped with a heat-reflecting blanket and the second shielding was provided by a thick styrofoam cube covering the sensor and the entire exposed portion of the pier.

For the purposes of this work, the 18 month three-component continuous digital recordings

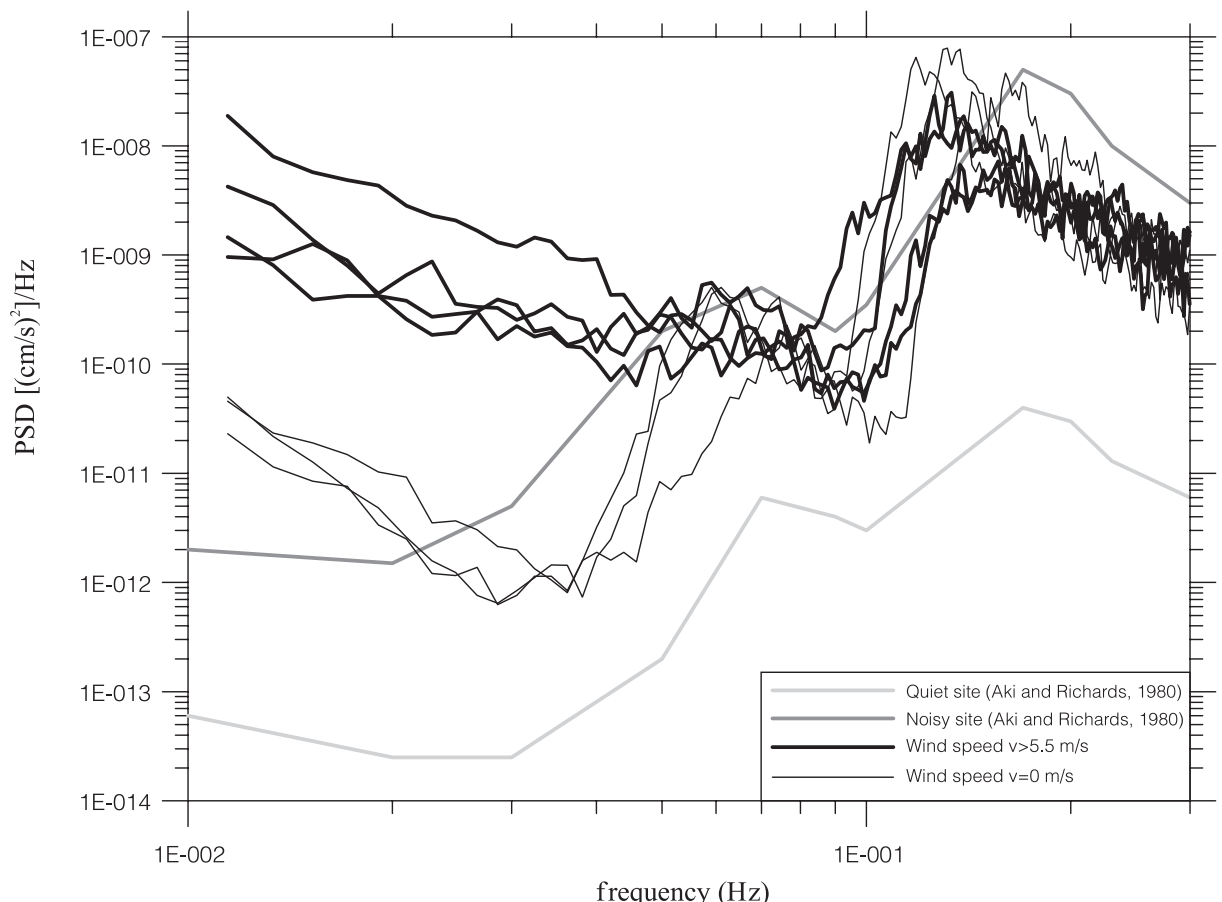

Fig. 4. Velocity power spectral density of the N-S component long period ambient seismic for wind and quiet meteorological conditions in winter 
were monitored to reveal noise level variations at different frequency bands. Figure $3 \mathrm{a}-\mathrm{d}$ shows an example of low-pass filtered $\left(f_{c}=0.1 \mathrm{~Hz}\right)$ records of seismic background noise. Depending on the season and on the wind speed, amplitudes differ substantially: noise amplitudes are higher in fall and winter than in spring and summer and are about the same for vertical and horizontal components on calm days. On the other hand, horizontal long period noise is stronger than in vertical components on windy days. These results suggested that a correlation exists between noise levels and meteorological conditions at the site. This correlation could be investigated using the data of a complete meteorological station located at few tens of meters from the seismic cave.

Noise samples of 60 min length were taken from the continuous data recording at intervals of $24 \mathrm{~h}$, always at $3 \mathrm{AM}$ local time in order to reduce man-made noise influence. Data were acquired with 31.25 samples per second. For the analyzed times, the record sections and related velocity Power Spectral Densities (PSD) were plotted jointly and visually inspected. Earthquakes, explosions and other transient signals were excluded from all noise samples. The smoothed PSD was calculated following Bendat and Piersol (1986) for 50\% overlapping record segments with a length of 16384 samples, corresponding to individual segment lengths of $524.3 \mathrm{~s}$. The PSD was calculated for each segment, after removing the linear trend and tapering with a Hanning window, and then averaged over all segments. The PSD was finally corrected for the instrumental response and presented in units of velocity power spectral density $\left[(\mathrm{cm} / \mathrm{s})^{2} / \mathrm{Hz}\right]$.

Firstly, long period $(f<0.04 \mathrm{~Hz})$ seismic noise at EBR was characterized. Figure 4 shows a power spectra plot for winter (January and February, 2000) at EBR where strong long period noise for wind speeds exceeding $5.5 \mathrm{~m} / \mathrm{s}$ can be seen. A representation of the average PSD amplitude over the frequency band $0.02<f<0.03$ $\mathrm{Hz}$ as a function of wind speed better shows this trend (fig. 5). For wind speeds of 0 to $15.5 \mathrm{~m} / \mathrm{s}$ noise levels may vary up to $45 \mathrm{~dB}$ for the horizontal components and, taking into account the good thermal shielding of the seismometer, they are related to tilts due to wind-generated local pressure fluctuations. The coherence func-

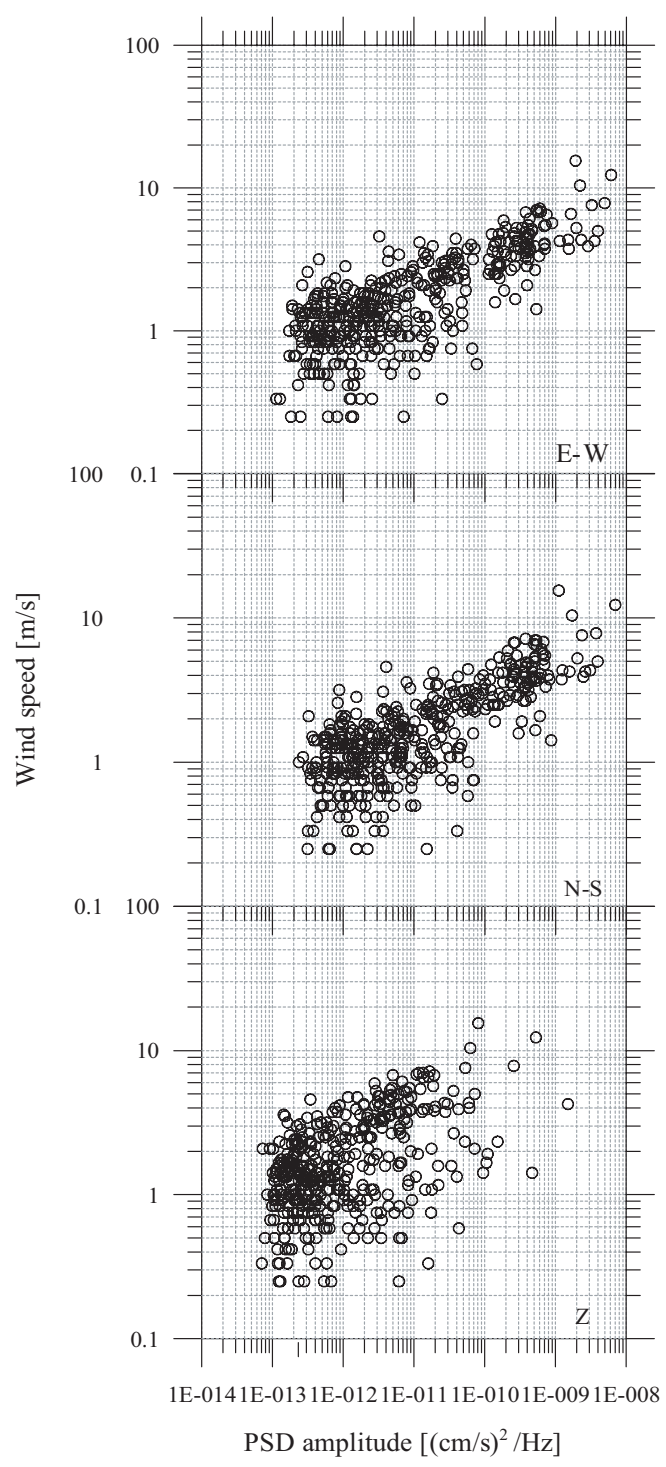

Fig. 5. Variation of the average long period velocity power spectral density amplitude $(0.02<f<0.03 \mathrm{~Hz})$ with wind speed. Power spectra curves are compared with the high and low noise model according to Aki and Richards (1980).

tion between local pressure fluctuations and seismic data could have been estimated with seismic data if we had had microbarometric data available at the seismic cave (Beauduin 


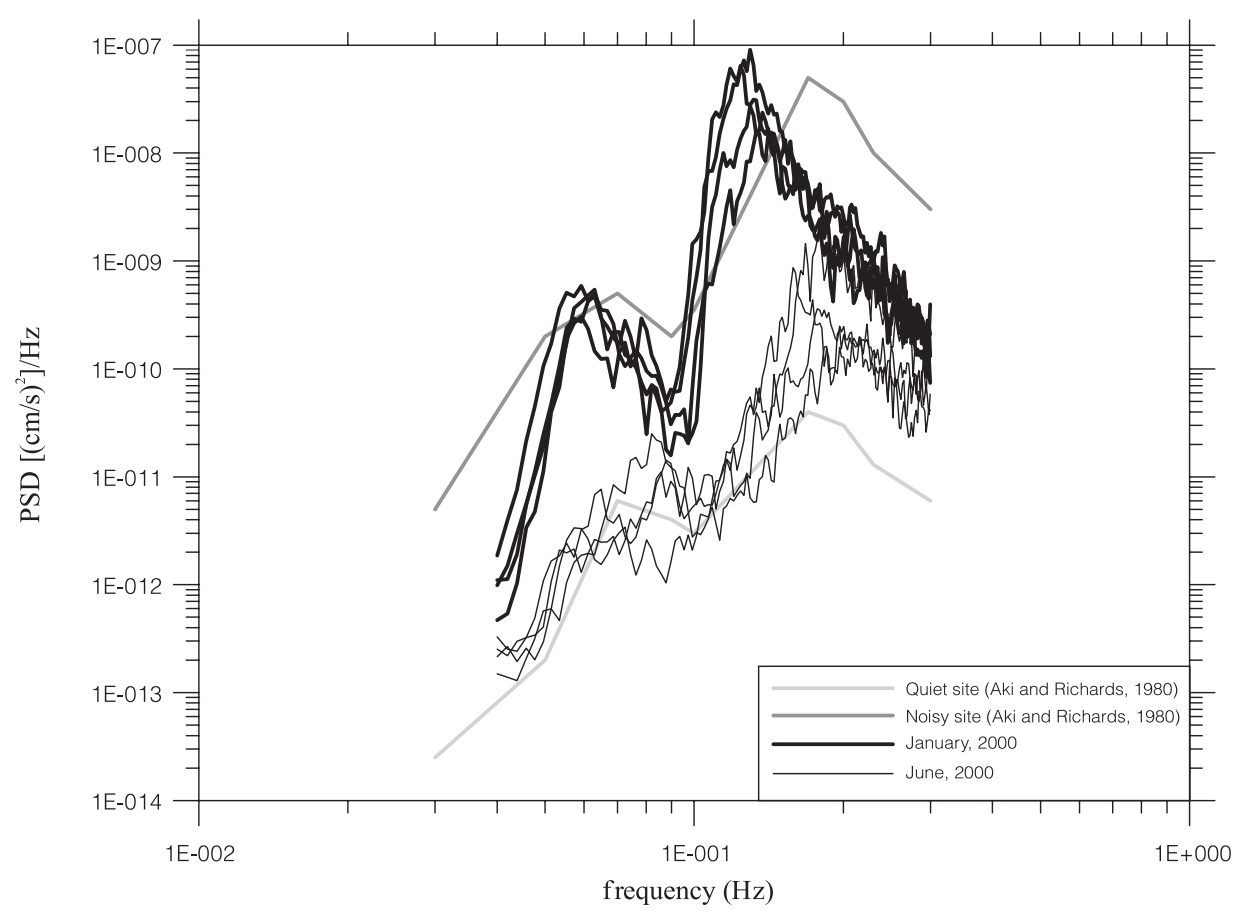

Fig. 6. Velocity power spectral density of vertical component primary and secondary microseisms $(0.03<f<0.3$ $\mathrm{Hz}$ ) for January and June, 2000. Power spectra curves are compared with the high and low noise model according to Aki and Richards (1980).

et al., 1996). According to Sorrells et al. (1971), most of this noise could be eliminated by placing the seismometer several hundred meters below the surface.

Secondly, the seasonal variation of noise levels at the frequency band $0.04<f<0.3 \mathrm{~Hz}$ was characterized. As fig. 6 shows, the amplitude of the primary and secondary microseisms PSD peaks presents the variations between winter and summer (Vila, 1998; Stutzmann et al., 2000) already observed at other seismic stations. This behavior is better seen in figs. 7 and 8 , where the seasonal variation of the velocity power spectra peak of three-component primary and secondary microseisms is shown. The maximum noise levels occur in winter and the minimum in summer, as a consequence of the intensity of storms, which is higher in winter than in summer and the presence, on the average, of a greater number of noise sources (cyclone low-pressure areas) also in winter than in summer (Vila, 1998; Stutzmann et al., 2000). It is also observed that the amplitude of the seasonal variation is higher for secondary (up to $52 \mathrm{~dB}$ ) than for primary (up to $44 \mathrm{~dB}$ ) microseisms. On the other hand, there is also a variation of the dominant frequency of the microseismic peak (fig. 6). In fall and winter, the frequency of the main peak is shifted towards lower frequencies (Stutzmann et al., 2000). The seasonal variation of the frequency of the threecomponent main noise peak, which is opposite to the velocity PSD amplitude evolution, is shown in fig. 9. According to Stutzmann et al. (2000), the shift of the dominant frequencies toward lower frequencies is due to an increase in large storms in winter with respect to the rest of the year.

For the sake of clarity in the figures, the variations of seismic background noise level at high frequencies have been plotted using spectragrams (PSD as a function of frequency 


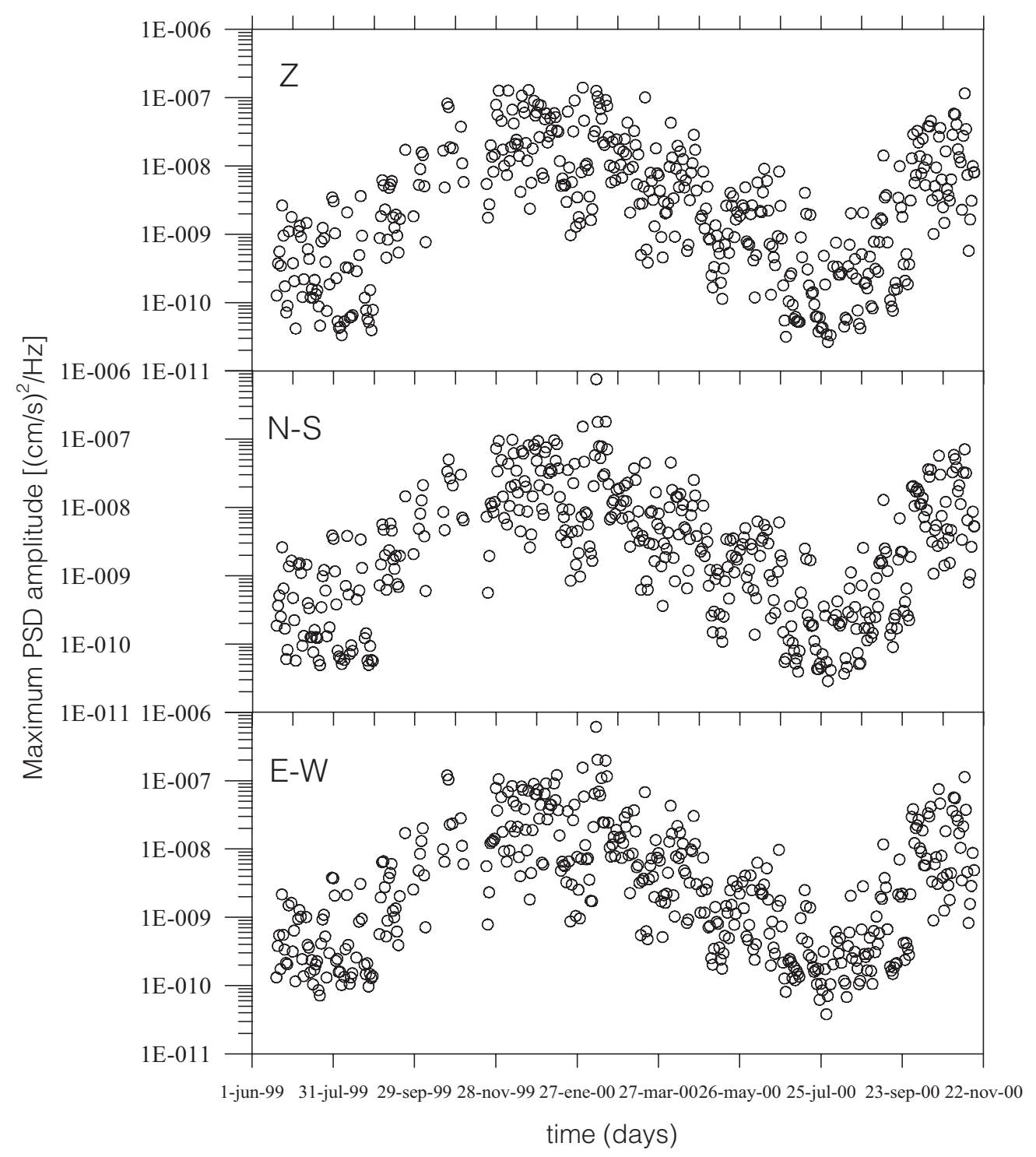

Fig. 7. Seasonal variation of the velocity power spectra peak for three-component primary microseisms.

and time). Figure 10a,b shows the spectragrams for three months in the time periods December, 1999 to February, 2000 and June, 2000 to August, 2000, for the frequency band $0.3<f<2$ Hz. The generally higher noise levels in winter than in summer are observed for this frequency band, however, the seasonal variations are higher for frequencies close to the microseismic peak (between 0.1 and $0.2 \mathrm{~Hz}$ in this site). Nevertheless, other peaks are observed in the noise spectra. To assess their correlation, hourly averaged wind speed data has been overlaid onto PSD data. As 
fig. 10a,b shows, a generally good correlation is observed between high wind speed and seismic background noise levels. The dense vegetation at this site (a great number of trees were planted some decades ago) enhances the coupling of wind energy into seismic noise at high frequencies.

The presence of spectral noise peaks at EBR related to resonance due to soft-soil cover was also checked. Following Nakamura (1989), the most prominent spectral noise peak in the horizontal to vertical component spectral ratio occurs at the resonance frequency of the shear wave. This technique has been widely applied (e.g., Lachet and Bard, 1994; Konno and Ohmachi, 1998) to estimate site amplification effects from single station noise recordings. Figure 11a shows an

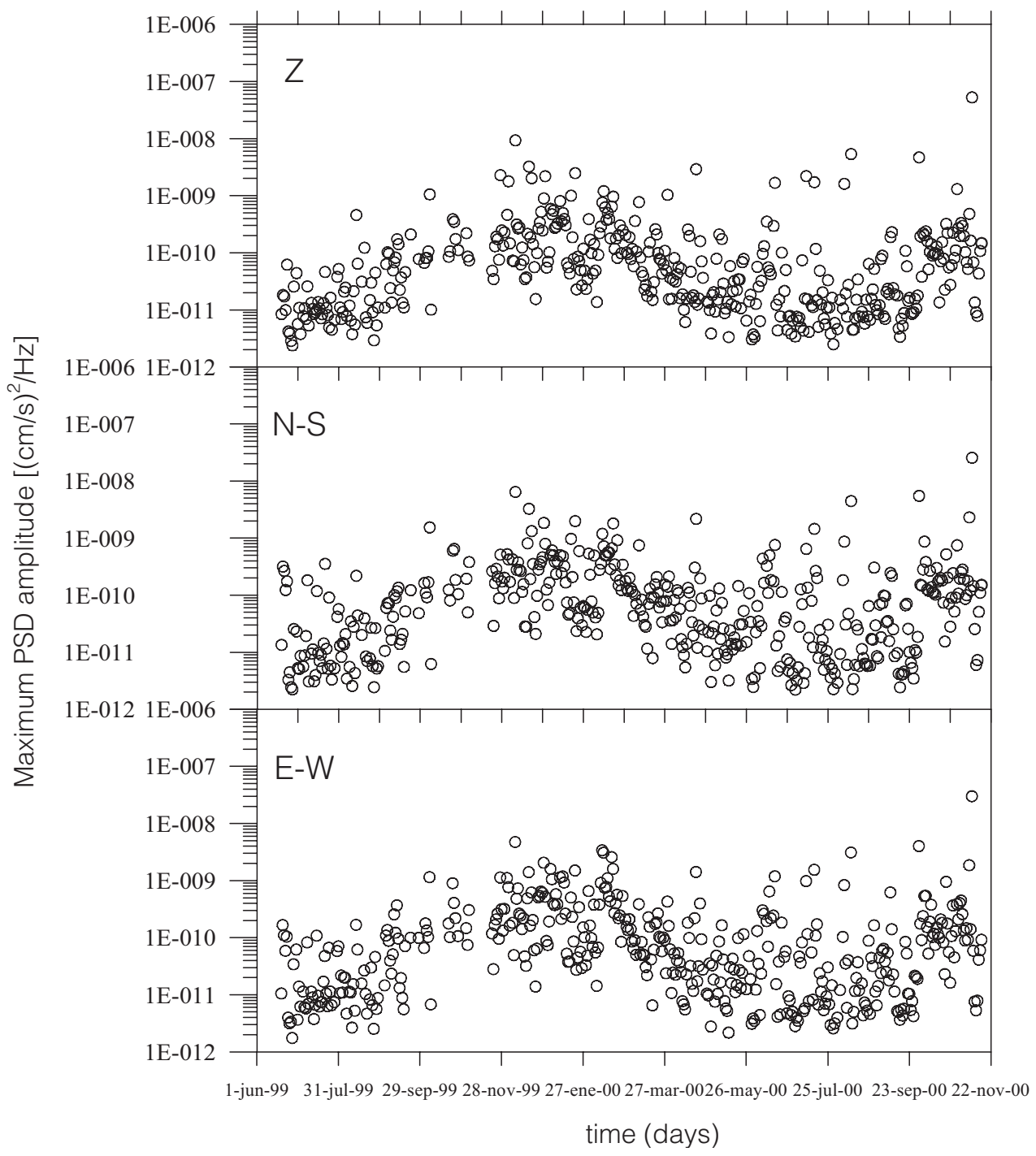

Fig. 8. Seasonal variation of the velocity power spectra peak for three-component secondary microseisms. 


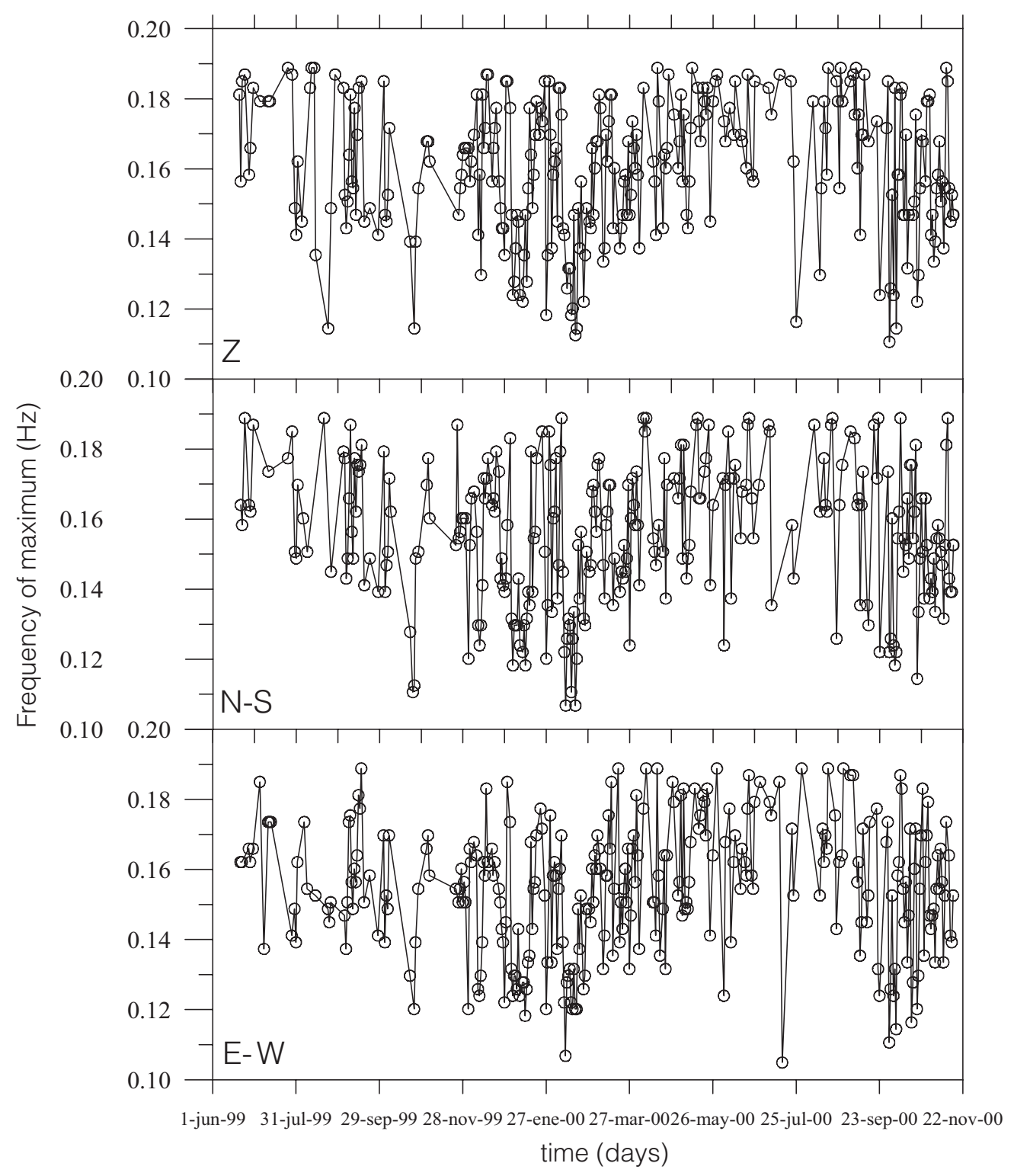

Fig. 9. Seasonal variation of the frequency for the three-component velocity power spectra peak of secondary microseisms.

example of the $\mathrm{H} / \mathrm{V}$ spectral ratio calculated for a one-hour noise sample on January 2000 at $\mathrm{EBR}$, in which the fundamental resonance frequency occurring at $0.5 \mathrm{~Hz}$ is clearly observed.
The frequency of the H/V maximum for all the 18 months noise data is shown in fig. $11 \mathrm{~b}$. It can be observed that the fundamental soft layer resonance frequency for this site (300 m depth Quater- 

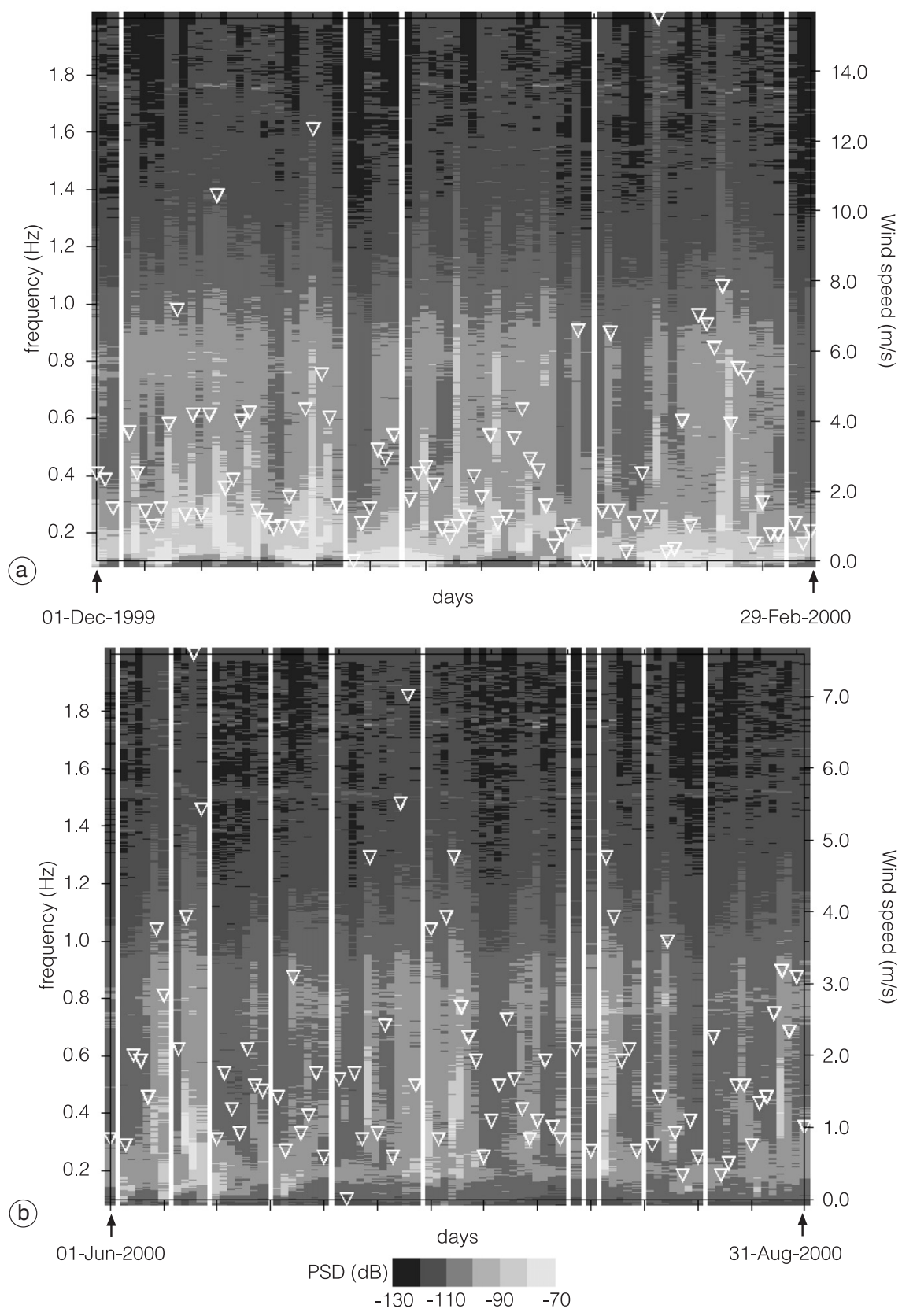

Fig. 10a,b. Spectragrams for: a) 1st December 1999 to 29th February 2000; b) 1st June 2000 to 31st August 2000. The E-W component PSD daily variation from noise samples at 3 AM local time for the frequency band $0.1<f<2 \mathrm{~Hz}$ is shown. A correlation between hourly averaged wind speed (white triangles) and seismic background noise is observed (note the change in wind speed scale in (b) with respect to (a)). White vertical stripes indicate days for which there is no data. 

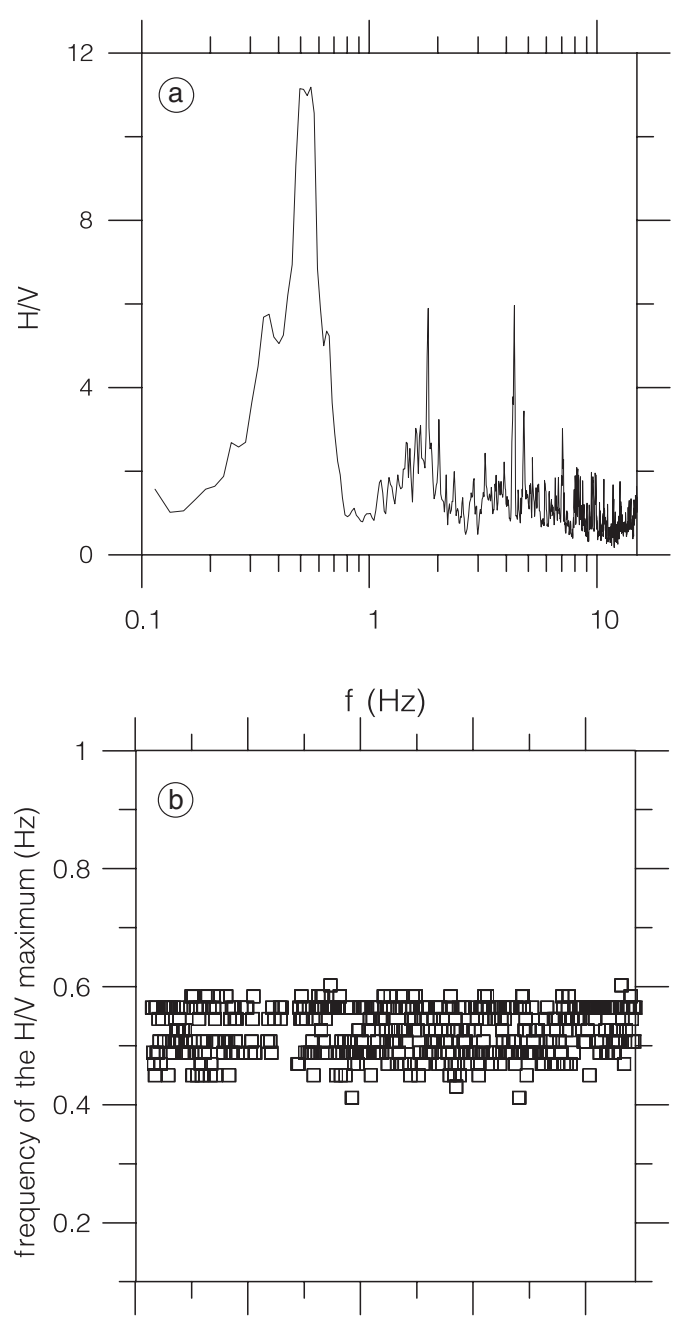

18-jun-99 16-oct-99 13-feb-00 12-jun-00 10-oct-00

Fig. 11a,b. a) Horizontal to vertical component (H/V) spectral ratio for $1 \mathrm{~h}$ noise samples at $3 \mathrm{AM}$ local time on 30th January 2000; b) frequency of the maximum $\mathrm{H} / \mathrm{V}$ spectral ratio for all the analyzed noise samples from 18th June 1999 to 14th November 2000.

nary sediments) ranges between 0.4 and $0.6 \mathrm{~Hz}$. However, although fig. 10a,b shows horizontal component spectral data, for which site effects should be larger, no clearly developed peak in the PSD for this frequency range is observed, which may indicate that it is buried in the dominat- ing noise generated by other sources (wind or man-made noise) (Borrmann et al., 1997).

Finally, the frequency band $2<f<15.62$ $\mathrm{Hz}$ was analyzed. Figure 12a,b shows the spectragram at this frequency band for the winter and summer seasons. From this figure, no seasonal variations of seismic background noise can be inferred for this frequency band. On the other hand, it can be observed that whereas for the frequencies ranging between 4 and $8 \mathrm{~Hz}$ approximately, noise levels are in general below the high-noise model of Aki and Richards (1980), a noisy behavior from 8 to $14 \mathrm{~Hz}$ is generally observed in this site, independently of the season and even at 3 AM local time when man-made noise sources are minimized.

From the previous noise conditions analysis at EBR site over the frequency band $0.01<f<$ $<15 \mathrm{~Hz}$, and once stated that it represents a coastal seismic station, it can be inferred that EBR station can accomplish the site requirements of modern broadband seismic instrumentation for low frequencies. Noise levels for long and medium periods are between the high-noise and low-noise model curves according to Aki and Richards (1980). However, there is a strong long period horizontal noise at $f<0.04 \mathrm{~Hz}$ caused by wind-generated local atmospheric pressure field fluctuations. In order to reduce the noise level of seismic data at very long periods, the data of a microbarometer installed at the seismic cave could be used in the future. However, it is a noisy site from the point of view of high frequencies mainly due to the vicinity of man-made noise sources.

\section{Summary and conclusions}

In this paper, the main characteristics of EBR seismic station have been presented. Firstly, the past and present instrumentation operating at EBR has been described and the availability of all seismological data since the first recorded earthquake on April 25th, 1905 has been emphasized. The historical relevance of EBR seismological station claimed a quantification of the quality of the site. Thus, noise conditions for the frequency range $0.01<f<15 \mathrm{~Hz}$ have been investigated through the spectral analysis of 60 


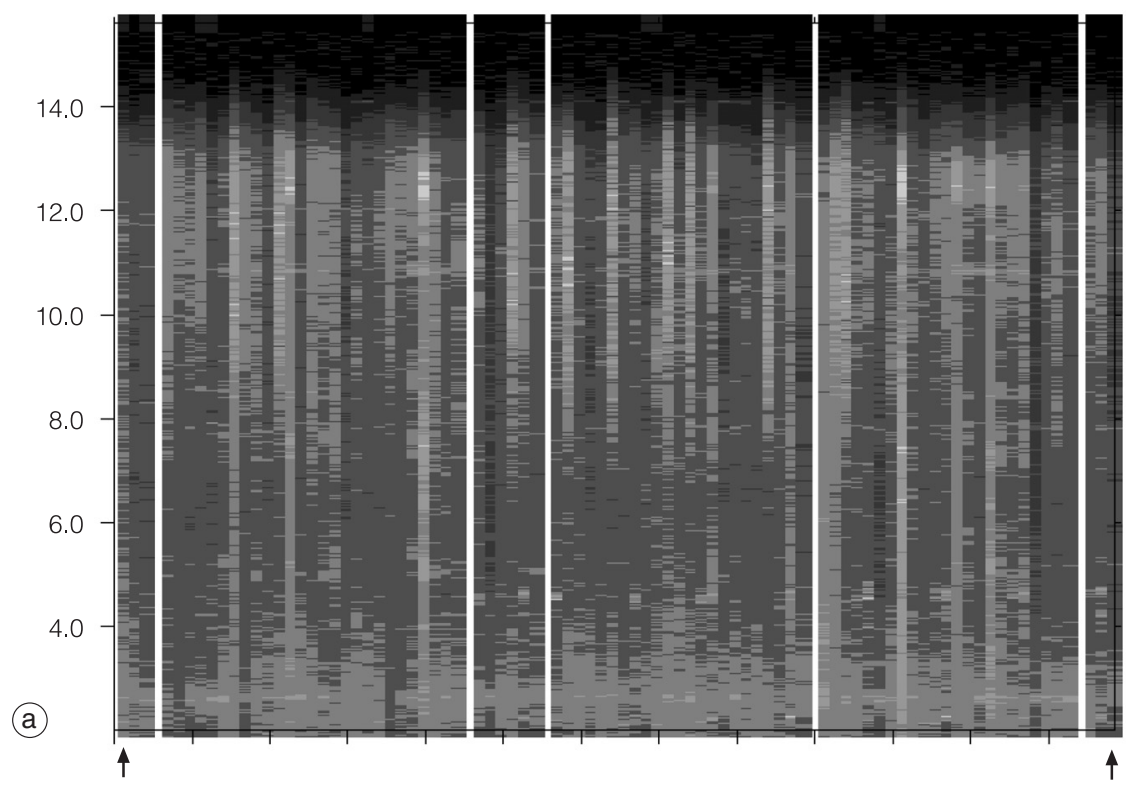

01-Dec-1999

29-Feb-2000

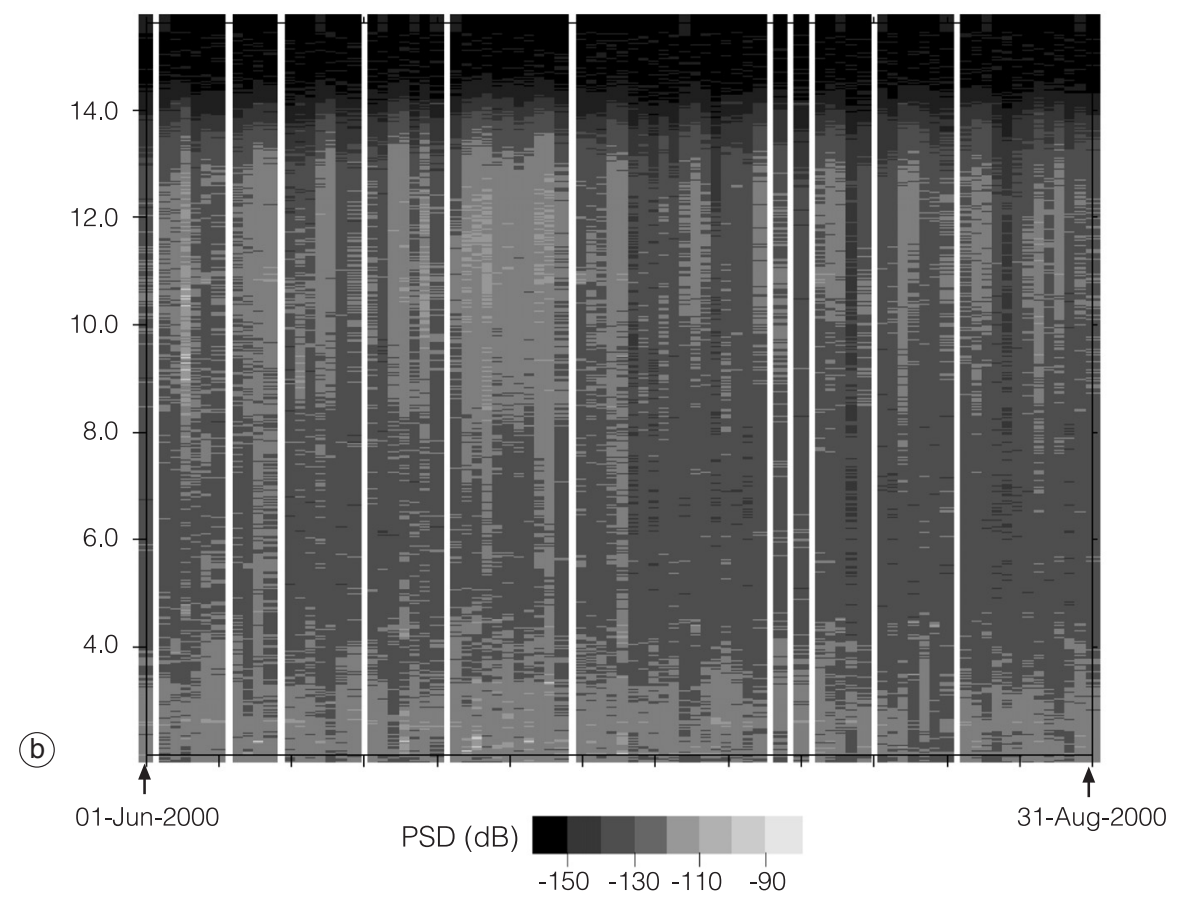

Fig. 12a,b. Spectragrams for: a) 1st December 1999 to 29th February 2000; b) 1st June 2000 to 31st August 2000. The vertical component PSD daily variation from noise samples at $3 \mathrm{AM}$ local time for the frequency band $2<f<15.62 \mathrm{~Hz}$ is shown. White vertical stripes indicate days for which there are no data. 
min in length noise samples taken at $3 \mathrm{AM}$ local time at an interval of $24 \mathrm{~h}$ during 18 months. The following environmental noise characteristics have been observed:

- For long periods $(f<0.04 \mathrm{~Hz})$ and wind speeds ranging from 0 to $15.5 \mathrm{~m} / \mathrm{s}$, seismic noise levels may vary up to $45 \mathrm{~dB}$ for the horizontal components. These variations are related to tilts due to wind-generated pressure fluctuations.

- The seasonal variation of noise levels at the frequency band $0.04<f<0.3 \mathrm{~Hz}$ shows that the amplitude of the seasonal variation is higher for secondary (up to $52 \mathrm{~dB}$ ) than for primary (up to $44 \mathrm{~dB}$ ) microseisms.

- A seasonal variation of the frequency of the three-component main noise peak is suggested in this site and its variation is opposite to the velocity power spectral density amplitude evolution.

- The fundamental soft layer resonance frequency for this site (300 m depth Quaternary sediments) ranges between 0.4 and $0.6 \mathrm{~Hz}$, and no clearly developed peak in the PSD for this frequency range is observed, which may indicate that it is buried in the dominating noise generated by other sources (wind or man-made noise).

- No seasonal variation of seismic background noise is observed at high frequencies $(f>2 \mathrm{~Hz})$.

- Noise levels are above the high-noise model of Aki and Richards (1980) for the frequency band between 8 and $14 \mathrm{~Hz}$, even at 3 AM local time when man-made noise sources are minimized.

- EBR site can accomplish the site requirements of modern broadband seismic instrumentation for low frequencies. The long period horizontal noise at $f<0.04 \mathrm{~Hz}$ caused by wind-generated local atmospheric pressure field fluctuations could be reduced in the future using the data of a microbarometer installed at the seismic cave. However, it is a noisy site from the point of view of high frequencies mainly due to the vicinity of man-made noise sources.

\section{Acknowledgements}

The author is very grateful to Dr. Suzan Van Der Lee, Mark Van Der Meijde and Federica
Marone from Eidgenoessische Technische Hochschule (ETH), Zurich, Switzerland, for making available the noise recordings. The author also very much appreciates the information provided by Dr. Josep Batlló on the characteristics of historical seismographs that had operated at the Ebre Observatory.

\section{REFERENCES}

AKI, K. and P.G. RICHARDS (1980): Quantitative Seismoloy: Theory and Methods (Freeman and Co., S. Francisco), p. 497.

BATLLÓ, J. and J.O. CARDÚS (1993): Historic seismograms and materials preserved at the seismic section of the Observatori de l'Ebre, in Proceedings of the XXIII General Assembly of the European Seismological Commission, Praha, 7-12 September 1992, vol. 1, 232-235.

BAtlló, J. and A. Ugalde (2000): Els sismògrafs de l'Observatori de l'Ebre, in Actes de les $V$ Trobades d'Història de la Ciència $i$ de la Tècnica, Barcelona, Spain, 161-165.

Beauduin, R., P. Lognonne, J.P. Montagner, S. CACHO, J.F. KARCZEWSKI and M. MORAND (1996): The effects of the atmospheric pressure changes on seismic signals or how to improve the quality of a station, Bull. Seismol. Soc. Am., 86, 1760-1769.

Bendat, J.S. and A.G. PIERSol (1986): Random Data: Analysis and Measurement Procedures (Wiley-Interscience, New York), p. 400.

Borrmann, P. (1999): New Manual of Seismological Observatory Practice (chapter 4), http:/www.seismo. com/msop/nmsop/nmsop.html.

Borrmann, P., K. Wylegalla and K. Klinge (1997): Analysis of broadband seismic noise at the German Regional Seismic Network and search for improved alternative station sites, J. Seismol., 1, 357-380.

CESSARO, R.K. (1994): Sources of primary and secondary microseisms, Bull. Seismol. Soc. Am., 84 (1), 142-148.

Friedrich, A., F. KRÜGER and K. KLINGE (1998): Ocean-generated microseismic noise located with the Gräfenberg array, J. Seismol., 2, 47-64.

HAUBRICH, R.A. (1967): Microseisms, in International Dictionary of Geophysics, edited by S.K. RUNCORN (Pergamon Press, London), 975-977.

KonNO, K. and T. OHMACHI (1998): Ground motion characteristics estimated from spectral ratio between horizontal and vertical components of microtremor, Bull. Seismol. Soc. Am., 88, 228-241.

LACHET, C. and P.-Y. BARD (1994): Numerical and theoretical investigations on the possibilities and limitations of the 'Nakamura's' technique, J. Phys. Earth, 42, 377-397.

LONGUET-HigGins, M.D. (1950): A theory on the origin of microseisms, Phil. Trans. R. Soc. London A., 243, 1-35.

NAKAMURA, Y. (1989): A method for dynamic characteristics estimation of subsurface using microtremor on the groud surface, Q. Rep. Railway Tech. Res. Inst., 30, 25-33. 
Richter, C.F. (1958): Elementary Seismology (W.H. Freeman and Company), San Francisco, 711-715.

Sorrells, G.G., J.A. MCDONALD, Z.A. DER and E. Herrin (1971): Earth motion caused by local atmospheric pressure changes, Geophys. J. R. Astron. Soc., 26, 83-98.

Stutzmann, E., G. Roult and L. Astiz (2000): GEOSCOPE station noise levels, Bull. Seismol. Soc. Am., 90 , 690-701.

SusAgnA, T., J. BATLló and A. RocA (1997): Seismographs, seismograms and related materials preserved in Catalonia, Cahiers du Centre Européen de Geodynamique et de Séismologie, 13, 37-48.

VILA, J. (1998): The broadband seismic station CAD (Túnel del Cadí, Eastern Pyrenees): Site characteristics and background noise, Bull. Seismol. Soc. Am., 88, 297-303.

Withers, M.M., R.C. Aster, C.J. Young and E.P. CHAEL (1996): High-frequency analysis of seismic background noise as a function of wind speed and shallow depth, Bull. Seismol. Soc. Am., 86, 1507-1515.

YounG, C.J., E.P. CHAEL, M.M. WITHERS and R.C. ASTER (1996): A comparison of the high-frequency $(>1 \mathrm{~Hz})$ surface and subsurface noise environment at three sites in the United States, Bull. Seismol. Soc. Am., 86, 1516-1528.

(received November 21, 2002; accepted March 19, 2003) 